\title{
Severe X-linked intellectual disability, Gustavson type
}

INSERM

\section{Source}

INSERM. (1999). Orphanet: an online rare disease and orphan drug data base. Severe Xlinked intellectual disability, Gustavson type. ORPHA:3078

Severe X-linked intellectual disability, Gustavson type is characterised by X-linked mental retardation, microcephaly, optical atrophy with impaired vision or blindness, a severe hearing defect, facial dysmorphology, spasticity, epileptic seizures and restricted joint movement. It has been described in seven children from two generations of a Swedish family. All patients died in during early childhood. 